\title{
\begin{tabular}{l|l|l|l|l}
\hline $\mathrm{M}$ & $\mathrm{R}$ & $\mathrm{S}$ & Internet Journal of & Nitride Semiconductor Research \\
\hline
\end{tabular}
}

Volume 2, Article 41

\section{Characteristics of Indium-Gallium-Nitride Multiple-Quantum-Well Blue Laser Diodes Grown by MOCVD}

\author{
M.P. Mack \\ Electrical and Computer Engineering and Materials Departments, University of California, Santa Barbara \\ and \\ Wright Laboratories (WL/AADD) \\ A. Abare, M. Aizcorbe, Peter Kozodoy, S. Keller, U. K. Mishra, L. Coldren, Steven DenBaars \\ Electrical and Computer Engineering and Materials Departments, University of California, Santa Barbara
}

This article was received on September 16, 1997 and accepted on September 17, 1997.

\begin{abstract}
Room temperature (RT) pulsed operation of blue $(420 \mathrm{~nm})$ nitride based multi-quantum well (MQW) laser diodes grown on c-plane sapphire substrates with lifetimes exceeding 6 hours have been demonstrated. Threshold current densities as low as $12.7 \mathrm{kA} / \mathrm{cm}^{2}$ were observed for $10 \times 1200 \mu \mathrm{m}$ lasers with uncoated reactive ion etched (RIE) facets. The emission is strongly TE polarized and has a sharp transition in the far field pattern above threshold.
\end{abstract}

\section{Introduction}

Since the report of the first RT pulsed operation of nitride based laser diodes by researchers at Nichia Chemical Industries two years ago [1] a handful of research groups in Japan [2] [3] [4] and recently Cree Research in collaboration with North Carolina State and Brown Universities in the United States havereported pulsed operation, and in the case of Cree, short lived (15 sec) continuous wave (CW) operation [5]. Nichia now reports RT CW operation with lifetimes in excess of 1,000 hours [6]. Despite this significant progress by Nichia and others, the actual lasing mechanism and its relationship to the structural and electrical properties of these materials is not well understood.

\section{Experiment}

The laser structure shown in Figure 1 was grown on c-plane sapphire using a combination of atmospheric and low pressure MOCVD in a two-flow horizontal reactor. The chemical precursors used were trimethylgallium (TMGa), trimethylindium (TMIn), trimethylaluminum (TMAI), ammonia, bis(cyclopentadienyl)magnesium (Cp2Mg) and disilane.

The lasers facets were formed by $\mathrm{Cl}_{2}$ reactive ion etching of $125 \mu \mathrm{m}$ wide mesas of various lengths ranging from $400 \mu \mathrm{m}$ to $2,000 \mu \mathrm{m}$. P-contact stripes were subsequently formed in the center of these large mesas with widths ranging from $3 \mu \mathrm{m}$ to $20 \mu \mathrm{m}$. The $\mathrm{n}$ and $\mathrm{p}$-contacts were formed by electron beam evaporation of Ti/Al/Ni/Au and $\mathrm{Ni} / \mathrm{Au}$ respectively. Fabricated lasers were tested under pulsed operation with a duty cycle of about $0.025 \%$.

\section{Results}

Figure 2 gives a photo of a $20 \times 400 \mu \mathrm{m}$ device operating above threshold showing the narrowed far field with some lateral interference due to multi-lateral mode operation. The projected far field pattern narrows abruptly at threshold. Using the central spot the vertical and lateral far-field half-angles were approximately $10^{\circ}$ and $3^{\circ}$, respectively, for the $20 \mu \mathrm{m}$ wide stripe. 
A typical light vs. current (LI) curve is shown in Figure 3. The LI curve shows characteristic super linear behavior. The highest differential efficiency was $1.1 \%$. Output powers of these devices were limited by heating during the pulses. Nevertheless, peak powers as high as $17.6 \mathrm{~mW}$ were obtained. Most devices gave outputs in excess of $10 \mathrm{~mW}$. Device yield was well above $50 \%$. The emission above threshold was strongly TE polarized with an extinction ratio in excess of 60 as shown in Figure 4.

Spectra were collected above and below threshold using an optical spectrum analyzer with a resolution of $0.1 \mathrm{~nm}$. A strong, well-defined mode spectrum appears at threshold as shown in Figure 5. The resolution is not sufficient to resolve the expected individual mode spacing for the cavity lengths tested. As a result the width of the observed peaks corresponds to the analyzer resolution. The lasing spectrum does, however, show an envelope modulation with a peak spacing around $0.35 \mathrm{~nm}$ similar to that observed by Nakamura et al.[1]. The origin of this modulation is still unclear.

Diodes of different length and stripe width gave a range of threshold current densities as shown in Figure 6, Figure 7 and Figure 8. As indicated the threshold current density decreased for increasing width and length in rough agreement with the expected reduction in cavity loss. With increasing cavity length the threshold current density approaches a minimum, indicating that internal losses (as opposed to mirror losses) dominate the cavity loss. The lowest threshold current density observed was $12.7 \mathrm{kA} / \mathrm{cm}^{2}$ for a $10 \times 1200 \mu \mathrm{m}$ laser bar with uncoated facets at room temperature. Devices longer than $1200 \mu \mathrm{m}$ could not be tested due to limitation in the pulse supply

A lifetime measurement done on a single device gave a lifetime greater than 6 hours. A 10x400 $\mu$ m device was operated pulsed above threshold at a power of $2.6 \mathrm{~mW}$. LI curves taken at intervals during the test are shown in figure 9. Initially the LI curves improve (lower threshold.) This is most likely due to annealing of the contacts and or thermal activation of the p-type dopant due to heating during operation. After 4 hours the threshold current density increases slightly until the device fails catastrophically between 6 and 8 hours due to shorting of the $p$-n junction.

\section{Conclusion}

Pulsed operation of $420 \mathrm{~nm}$ blue laser diodes with a threshold current density as low as $12.7 \mathrm{kA} / \mathrm{cm}^{2}$, output powers as high as $17.6 \mathrm{~mW}$ and lifetimes in excess of 6 hours are demonstrated. The power output of these devices is limited by heating during pulses. The lasing spectrum shows a "mode like" envelope modulation of unknown origin.

\section{Acknowledgments}

This work was supported by: DARPA (Dr.Anis Husain, Program Manager),ARO,NSF, HP Labs and Philips. The authors would like to acknowledge Daniel Cohen, Evelyn Hu, Milan Minsky, James Speck, $X$. Wu, John Bowers, Kehl Sink of UCSB and Bruce Young of Philips Research Labs for useful inputs and discussions.

\section{References}

[1] Shuji Nakamura, Gerhard Fasol, The Blue Laser Diode - GaN based Light Emitters and Lasers (Springer-Verlag, Heidelberg, 1997) .

[2] I. Akasaki, S. Sota, H. Sakai, T. Tanaka, M. Koike, H. Amano, Electron. Lett. 32, 1105-1106 (1996).

[3] K. Itaya, M. Onomura, J. Nishio, L. Sugiura, S. Saito, M. Suzuki, J. Rennie, S. Nunoue, M. Yamamato, H. Fujimoto, Y. Kokobun, Y. Ohba, G. Hatakoshi, M. Ishikawa, Jpn. J. Appl. Phys. 35, I1315-I1317 (1996).

[4]K. Domen et. al. , unpublished. Oral presentation at IEEE/LEOS Summer Topicals, Montreal, Canada, Aug. 1997.

[5] G.E. Bulman, K. Doverspike, S.T. Sheppard, T.W. Weeks, H.S. Kong, H.M. Dieringer, J.A. Edmond, J.D. Brown, J.T. Swindell, J.F. Schetzina, Electron. Lett. 33, 1556-1557 (1997).

[6]S. Nakamura et al., unpublished. Oral presentation at 24th ISCS, San Diego, CA, Sept. 9, 1997. 
GaN:Mg

$\mathrm{Al}_{0.1} \mathrm{GaH}: \mathrm{Mg}$

GaN:Mg

$10 \mathrm{x} \quad \operatorname{In}_{0.18} \mathrm{GaN}$ Ino.03 GaN: Si

GaN:Si

Alo.1GaV:Si

$\mathrm{In}_{0.1} \mathrm{GaV}: \mathrm{Si}$

GaH:Si
$0.1 \mu \mathrm{m}$

$0.4 \mu \mathrm{m}$

$0.03 \mu \mathrm{m}$

$30 \mathrm{~A}$

$70 \mathrm{~A}$

$0.03 \mu \mathrm{m}$

$0.4 \mu \mathrm{m}$

$0.1 \mu \mathrm{m}$

$3.0 \mu \mathrm{m}$

(0001) Sapphire

Figure 1. Epitaxial Structure

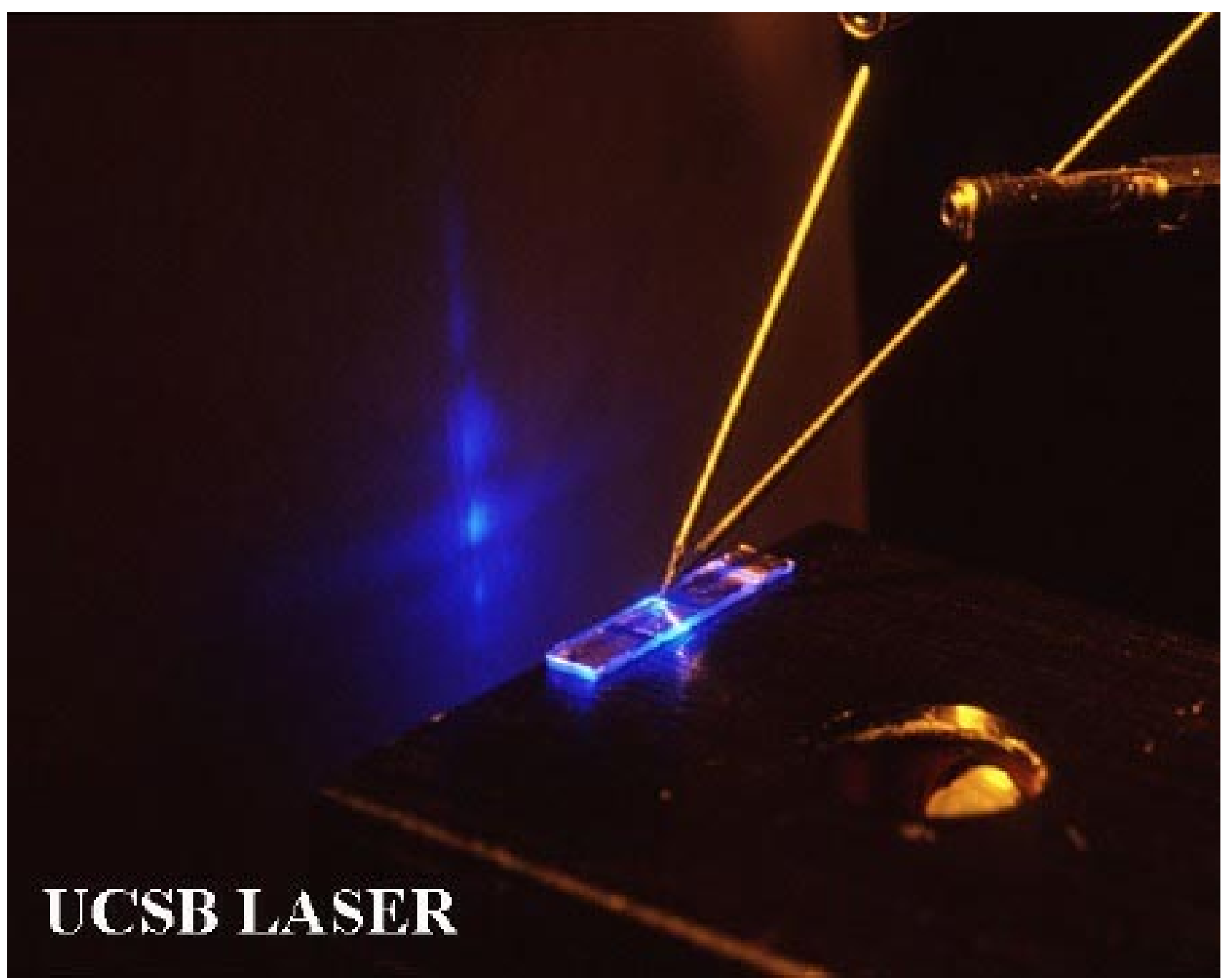

Figure 2. Photo of $20 \times 400 \mu \mathrm{m}$ device operating above threshold, showing elliptical far-field pattern. 

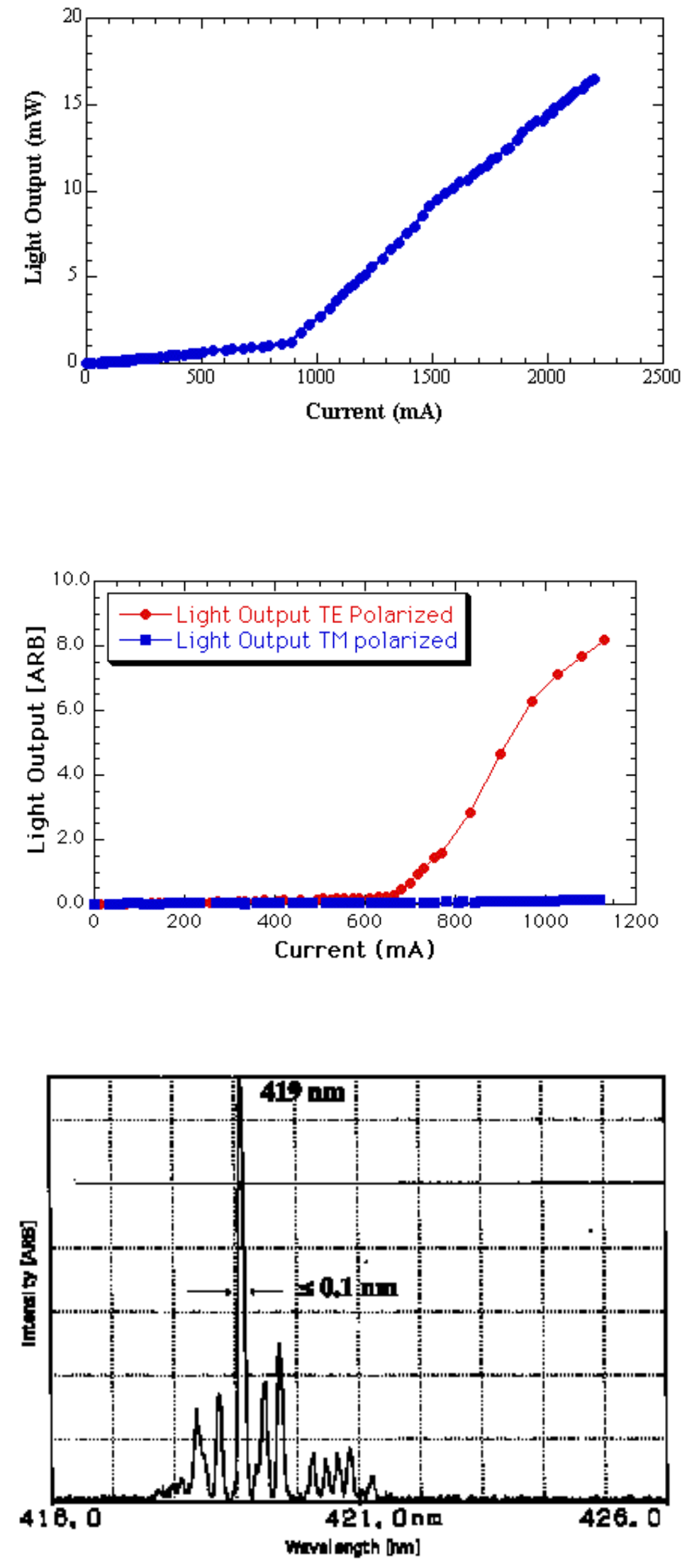

Figure 3. Light vs. current (LI) for $800 \mu \mathrm{m}$ long device with a $5 \mu \mathrm{m}$ stripe

Figure 4. Light vs. Current (LI) with polarizer parallel and perpendicular to junction plane

Figure 5. Above threshold spectrum for $400 \mu \mathrm{m}$ long device with a $5 \mu \mathrm{m}$ stripe width 

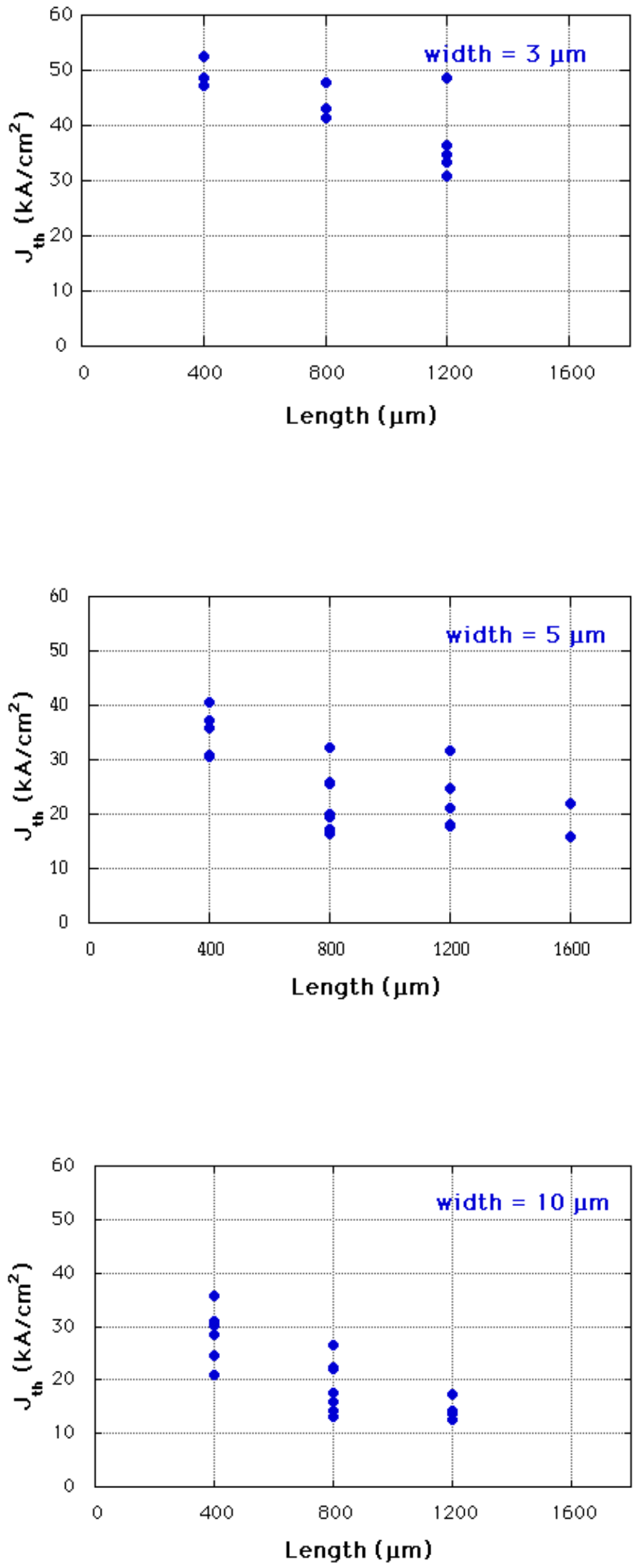

Figure 6. $J_{\text {th }}$ vs. laser length for $3 \mu \mathrm{m}$ stripe width

Figure $7 . J_{\text {th }}$ vs. laser length for $5 \mu \mathrm{m}$ stripe width
Figure 8. $J_{\text {th }}$ vs. laser length for $10 \mu \mathrm{m}$ stripe width 
